\section{Discussion}

The burden and pattern of psychiatric morbidity can be seen from available epidemiological data (Gureje et al, 1992; Abiodun, 1993). An idea of what is attainable within the primary health system can be seen from research done in other countries (Bilsker et al, 2007; Kates \& Mach, 2007; Paria \& Perez, 2007).

Nigeria is under-resourced in terms of psychiatric personnel and infrastructure. Access to care for the majority of people with mental illness is severely limited. Efforts to address this problem have so far been targeted at increasing the numbers of psychiatrists and psychiatric nurses, who are often located in urban specialist units.

The PHCs are the facilities closest to the majority of citizens. The research presented here shows that the knowledge base and interest of staff in the PHCs concerning mental illness are low. Further, unlike earlier reports on the matter (Gureje, 2005), it also shows that they do not have even the most basic drugs for treatment.

General practitioners have been a neglected force in mental healthcare planning in Nigeria. If the awareness, knowledge level and attitudes of GPs and PHC workers about mental health could be upgraded in a targeted way, it would lead to an increase in the numbers of people treated for their mental illnesses, especially those with 'minor' disorders. It could also create the beginning of a referral chain that would help to prevent the loss to clinical follow-up of individuals who have had specialised treatment in distant teaching hospitals or psychiatric hospital units.

\section{References}

Abiodun, O. A. (1993) A study of mental morbidity among primary care patients in Nigeria. Comprehensive Psychiatry, 34, 10-13.

Bilsker, D., Goldner, E. M. \& Jones, W. (2007) Health service patterns indicate potential benefit of supported self-management for depression in primary care. Canadian Journal of Psychiatry, 52, 86-95.

Gureje, O. (2005) Nigerian Mental Health Atlas 2005. WHO.

Gureje, O., Obikoya, B. \& Ikuesan, B. A. (1992) Prevalence of specific psychiatric disorders in an urban primary care setting. East African Medical Journal, 69, 282-287.

Kates, N. \& Mach, M. (2007) Chronic disease management for depression in primary care: a summary of the current literature and implications for practice. Canadian Journal of Psychiatry, 52, 77-85.

Paria, B. \& Perez, C. (2007) Schizophrenic disorder in primary care mental health. Aten Primaria, 39, 119-124.

World Health Organization (2001) Atlas: Country Profile of Mental Health Resources. WHO.

\title{
Psychiatry in Brunei Darussalam
}

\section{Reehan Sabri' ${ }^{1}$ and Ajmal-Khan Kudlebbai} ${ }^{1}$ Consultant Psychiatrist, Mental Health Unit, RIPAS Hospital, Bandar Seri Begawan, Brunei Darussalam BA 1710
email reehansabri@hotmail.com ${ }^{2}$ Staff Grade Forensic Psychiatrist, Three Bridges Regional Secure Unit, West London Mental Health NHS Trust, London, UK

$B^{n}$ runei Darussalam occupies a sliver of land on the northwest coast of the island of Borneo with a geographical area of just $5765 \mathrm{~km}^{2}$ (Government of Brunei, 2004). It is divided into the four districts: Brunei-Muara, Temburong, Tutong and Belait. Two-thirds of the land is covered by lush tropical rainforest and the climate is perpetually warm and humid. It is ruled by Sultan Hassan Al-Bolkiah, the head of a dynasty which has governed Brunei for 650 years.

The population of 374000 (United Nations Population Fund, 2005) enjoys one of the highest standards of living anywhere in the world, thanks to the discovery of oil in 1929, but the economy remains almost entirely dependent on oil and gas. The Bruneian population is $66 \%$ ethnic Malay and $15 \%$ ethnic Chinese; the rest are a mixture of indigenous and other races, such as the Ibans, who were once the feared headhunters of Borneo. There is also a large population of expatriate workers from the Indian subcontinent, South-East Asia, Australasia and Europe.

\section{Religion and culture}

The different cultural groups in Brunei have interesting beliefs about physical and mental health (Kumaraswamy, 2007). These often present a challenge to medical practitioners and psychiatrists in particular. In spite of the official state adoption of Islam, many Malays adhere to beliefs that are a mixture of Islam, misunderstandings of Islam, animism and Hinduism, and this religious stance is a major influence on their beliefs about health. The Chinese and indigenous communities also have their superstitions and forms of traditional medicine.

Unsurprisingly, therefore, the first line of help for any kind of ailment among Bruneians, particularly psychiatric, is the Malay shaman or Bomoh. Bomohs practise a type of folk medicine under the veneer of Islam but their heretical practices are frowned upon by the religious authorities. Their knowledge is passed from generation to generation (Abdul 
Kadir, 2006) and their treatments include calling upon spirits as well as the prescription of herbs, spells and charms. Threequarters of all Malay psychiatric patients will have consulted a Bomoh before resorting to mental health services (Salleh, 1989)

\section{Healthcare in Brunei}

Brunei has an extensive primary healthcare network, with accessible local clinics in most parts of the country. There is one hospital in each of the four districts, although most specialist services are provided in the capital city, Bandar Seri Begawan. There are a few individual private medical practitioners and one major private hospital.

\section{Psychiatric services}

There are two psychiatric departments in Brunei: one in the country's main hospital, Raja Isteri Pengiran Anak Saleha (RIPAS) Hospital in Bandar Seri Begawan, and a smaller department in Suri Seri Begawan (SSB) Hospital, in the town of Kuala Belait, in Belait District. There is significant stigma associated with mental illness and a certain amount of justified fear of psychiatric services. Before RIPAS Hospital was built, in 1984, there was a psychiatric unit in the old hospital known as 'Ward 5', which, by all accounts, was a classic asylum-style ward. The legacy of this unit continues to haunt Brunei's present-day mental health services. Even today, locals often refer to the hospital's modern mental health unit (MHU) as 'Ward 5' and recount with horror tales of screams and the sight of restrained patients.

There are four consultant psychiatrists (or 'specialists' as they are known in Brunei) in RIPAS Hospital and one in Kuala Belait. Although the specialists have expertise in different sub-specialties, there are no formal sub-specialist services.

The RIPAS MHU is a 20-bed ward with a virtually constant occupancy rate of at least $100 \%$. At any one time, almost half the patients are 'bed-blockers' with chronic mental illness, abandoned by their families and so lacking any appropriate discharge destination. In Brunei, there are no residential facilities for people who are mentally ill. The RIPAS MHU also doubles up as a day hospital but activities and the interventions of the highly able occupational therapists are severely limited by a lack of space. SSB Hospital has a handful of long-term in-patients. There is a nascent community psychiatric service based at RIPAS Hospital which administers depot antipsychotic medication in patients' homes and follows up some of the difficult-to-engage patients.

Electroconvulsive therapy is available and there is a reasonable array of modern antipsychotic drugs. However, the range of antidepressants is limited and hopelessly outdated. Drugs not on the formulary, such as clozapine and venflaxine, can be acquired on a named-patient basis, but delays of, on average, 3 months are usual. Their clinical usefulness is, hence, severely limited. Another curious problem is the highly variable supply of drugs. It is not uncommon to run out of stock without any prior warning.

Until recently, there was a single trained clinical psychologist, in RIPAS Hospital. With his recent departure and the absence of a successor, there is no effective alternative to pharmacotherapy, which exacerbates the problem of limited supplies and types of psychotropic drugs. However, there is a day centre for the rehabilitation of those with chronic mental illness, which has succeeded in helping a number of individuals back to employment.

\section{Mental health legislation}

The Lunacy Act 1929 (Attorney General's Chambers, 2004) allows for the detention of persons suspected of having a mental illness who are at risk. Unfortunately, the text of the Act is rather brief and imprecise. In practice, the relatives of any person suspected of having a mental illness may approach a magistrate and obtain a court order that authorises the involuntary detention of their family member. There is no right of appeal for the patient. Neither psychiatrists nor social workers are involved in this process; hence, there is potential for abuse of the law.

One of the laudable social welfare developments in Brunei is the Mental Health Allowance, which is a modest sum of money given monthly to those who are long-term mentally ill and incapable of working. The children of such individuals also receive an allowance. Furthermore, the Religious Department's treasury or 'Bait ul-Maal' distributes charitable donations to the needy members of Bruneian society, including those with psychiatric disorders and, in the case of converts to Islam, it also provides housing. Hence, it is unusual to see the type of grinding poverty often seen in Western countries among those who are mentally ill.

\section{Types of mental illness}

There are no documented prevalence studies of psychiatric disorders in Brunei, but the common illnesses which psychiatrists are familiar with are assessed and treated by the mental health services. Notably, suicide is virtually unheard of, as are cases of eating disorder. As one may expect, given the country's prohibition of alcohol, alcohol-related psychiatric disorder is uncommon, although not absent, since supplies are smuggled from across the border with Malaysia and small quantities can be legitimately brought into the country by non-Muslims, for personal consumption. Perhaps for the same reason, violence is also uncommon in Bruneian society. Any form of aggression often causes great consternation and may lead to a referral to psychiatric services.

One very worrying trend is the widespread use of methamphetamine, or Syabu (pronounced 'shaboo') as it is known locally. Despite severe laws on drug trafficking, there is anecdotal evidence of a pending methamphetamine epidemic among Bruneian youth. Consequently, people with methamphetamine-induced disorder are frequently admitted. Other common drugs of misuse include cannabis and solvents.

\section{Future developments}

Brunei Darussalam faces a number of challenges over the next few years, all of which are likely to affect its mental health services. Perhaps the most significant issue is the 
effect of the country's depleting oil reserves. The economy has not significantly diversified; if the prosperity dries up along with the oil wells, foreign workers are likely to leave. An exodus of Brunei's expatriates would be devastating for the mental health services, whose medical staff is composed entirely of foreigners. Psychiatry remains an unpopular choice of career with Brunei's small number of medical graduates, who are mostly trained in the UK, where they usually have a few weeks' exposure to psychiatry as undergraduates. A handful of Bruneian junior doctors are currently training as psychiatrists in nearby countries, but it is unlikely that a fully trained Bruniean psychiatrist will emerge for a number of years.

The mental health services face a number of tasks. The priorities are to raise the profile and understanding of psychiatry, as well as to undertake epidemiological research. There are plans to expand specialist services but these developments are already facing paralysing bureaucracy. Furthermore, there is a need for psychological treatments as well as better and newer drugs to be made available. The most ominous of unmet needs, however, is the establishment of drug treatment services. Finally, a new Mental Health Act is being drafted; it is hoped that it will afford greater protection to patients and will take account of the opinion of psychiatrists in the process of involuntary detention.

\section{References}

Abdul Kadir, A. H. (2006) Of roots, barks, paracetamol and EDTA. Malaysian Journal of Medical Sciences, 13, 1-6.

Attorney General's Chambers (2004) Lunacy Act 1929. Selected laws of Brunei. See http://www.agc.gov.bn/HTML/cap48.htm (accessed 30 August 2007)

Government of Brunei Darussalam (2004) Land and People. See http:// www.brunei.gov.bn/about_brunei/land.htm (accessed 25 August 2007).

Kumaraswamy, N.( 2007) Psychotherapy in Brunei Darussalam. Journal of Clinical Psychology, 63, 735-744

Salleh, R. S. (1989) The consultation of traditional healers by Malay patients. Medical Journal of Malaysia, 44, 3-13.

United Nations Population Fund (2005) Brunei Darussalam. UNFPA Worldwide: Population, health and socio-economic indicators. See http://www.unfpa.org/profile/brunei.cfm (accessed 25 August 2007).

\section{Nepal: trying to reach out to the community}

\section{Pramod M. Shyangwa ${ }^{1}$ MD and Arun Jha ${ }^{2}$ MPhil MRCPsych}

1'Associate Professor, Department of Psychiatry, BPK Institute of Health Sciences, Dharan, Nepal, email pshyangwa@yahoo.com

${ }^{2}$ Consultant Psychiatrist and Chairman, Psychiatry Section, Nepalese Doctors' Association; Logandene, Ashley Close, Hemel Hempstead, Herts HP3 8BL, UK, email arun.jha@HPT.nhs.uk

\begin{abstract}
andwiched between India and China, Nepal is a small $\checkmark$ landlocked lower-middle-income country in South Asia. Once a peaceful country, it is striving to overcome the legacy of a 10-year Maoist rebellion, a royal massacre and continuing political chaos. Nepal has been in dispute with neighbouring Bhutan over the repatriation of hundreds of thousands of refugees in several camps in Nepal. In addition, the country experiences frequent natural disasters (floods and landslides) and faces several environmental challenges, including deforestation and a population explosion in southern Nepal.

Slightly bigger than England in size, Nepal is $885 \mathrm{~km}$ long and $200 \mathrm{~km}$ wide, with an area of $147181 \mathrm{~km}^{2}$. It has a total population of nearly 28 million, and an annual population growth rate of $2.2 \%$. Life expectancy at birth is 63 years. Almost $90 \%$ of the population still live in rural areas and $38 \%$ live below the poverty line. Nepal has an annual per capita income of less than US\$300 (compared with US\$800 in India and over US\$1700 in China).
\end{abstract}

\section{Health resources and statistics}

Healthcare facilities in Nepal are generally poor (Box 1) and beyond the means of the majority. The provision of health services is constrained by low government spending, rugged terrain, lack of health education and poor public expectations. Most hospitals are located in urban areas; rural health facilities often lack adequate funding, trained staff and medicines and have poor infrastructure. In rural areas, patients sometimes have to be carried in a basket through the mountains for 3 or 4 days to reach the nearest primary care centre, which may in any case be devoid of trained medical personnel.

For administrative purposes, Nepal has been divided into five developmental regions, 14 zones and 75 districts. According to the institutional framework of the Department of Health Services, which is one of three departments under the Ministry of Health and Social Welfare, the sub-health posts (SHPs) are the first contact point for basic health services. Each level above the SHP is a referral point in a network from SHPs to health posts to primary care centres, and to district, zonal and regional hospitals, and finally to the specialist tertiary care centres in Kathmandu. Nepal currently has 10 tertiary care centres, 83 hospitals, 700 health posts and 3158 SHPs. There are a few private non-profit hospitals as well. Almost all the private sector hospitals, including those run by non-governmental organisations, and private, profit-oriented nursing homes are situated in the urban areas.

There are no national epidemiological data on mental health problems in Nepal, but data from other developing countries can help estimate the situation reasonably well. 